\title{
Abstracts of the meeting of the Clinical Genetics Society held at the Clinical Research Centre, Northwick Park Hospital, London on 8 and 9 November 1985
}

\author{
'Unequal Lyonisation' leading to division of a carrier zygote \\ into monozygotic twin girls discordant for Duchenne \\ muscular dystrophy: a hypothesis with clinical and molecu- \\ lar genetic support \\ J BURN*, S POVEY, Y BOYD, I W CRAIG, E A MUNRO, L WEST, \\ K HARPER, K DAVIES, P L PEARSON, D THOMAS, AND \\ M BARAITSER \\ ${ }^{*}$ Department of Human Genetics, 19 Claremont Place, \\ Newcastle upon Tyne.
}

Mouse human hybrids constructed using skin fibroblasts from monozygotic twin girls discordant for Duchenne muscular dystrophy have been analysed using $\mathrm{X}$ chromosome DNA probes. These hybrids survive in HAT medium only if the active $\mathrm{X}$ chromosome is retained. Inactive $\mathrm{Xs}$ tend to be lost. Hybridisation of the DNA from surviving clones with $\mathrm{X}$ linked probes identifies the allele on the active X. Preliminary experiments have shown clones from the affected girl to have the same allele, while those of the normal twin contain the alternate allele. This finding supports the hypothesis that $\mathrm{X}$ inactivation has, by chance, resulted in two contrasting cell masses in a female zygote carrying the Duchenne muscular dystrophy gene. This segregation led to twinning into a female pair, one of whom manifested the disease while the other was clinically normal. These results are of relevance to genetic counselling, the biology of the $\mathrm{X}$ chromosome, and the search for the Duchenne gene.

Gene deletion in Duchenne muscular dystrophy

N S T THOMAS*, H WILLIAMS*, P S HARPER*, AND

L M KUNKEL $\dagger$

${ }^{*}$ Section of Medical Genetics, University of Wales College of Medicine, Heath Park, Cardiff; and TChildren's Hospital Medical Center, Boston, USA.

A DNA probe (pERT 87) has recently been isolated by Kunkel et al (Proc Natl Acad Sci USA 1985;82:4778) from DNA corresponding to a region within the p21 band of the $\mathrm{X}$ chromosome deleted in a boy with Duchenne muscular dystrophy. This probe has been used to study families with DMD and Becker muscular dystrophy. From 91 affected males with DMD we have found five who were deleted for this probe; three were familial cases and two isolated. We have so far found no deletion in 34 Becker patients. No visible deletion has been shown in any of the deletion cases, nor does their phenotype differ obviously from other cases in respect to physical severity or mental retardation. Studies in these families using both dosage measurements and linkage analysis with several RFLPs identified by pERT 87 have identified the deletion in a number of potential female carriers within the families. The probe has been studied in chorion biopsy material and should allow specific prenatal diagnosis of affected males in deletion families.

Pedigree analysis of a deletion at $\mathrm{Xp21}$ in a family with Duchenne muscular dystrophy using prometaphase banding, flow cytometry, and DNA markers

D E WILCOX, A COOKE, E BOYD, J COLGAN, D AITKEN, AND M A FERGUSON-SMITH

Duncan Guthrie Institute of Medical Genetics, Yorkhill, Glasgow.

Eight-five west of Scotland males with Duchenne (DMD) and Becker muscular dystrophy have been investigated for deletions, 80 by chromosome analysis and 82 by DNA analysis. Seven deletions were detected in six families using the probe pERT $87-8$. Two cousins with DMD were suspected, on karyotype analysis, to have a small deletion at Xp21 and this was confirmed by flow cytometry and by demonstrating the deletion of the DNA markers $754,87-1$, and 87-8. Markers OTC, B24, and C7 are present in these patients. Flow cytometry showed that about $4800 \mathrm{~kb}$ were deleted in each case. Despite apparently similar deletions these cousins are discordant for severe mental handicap. Franke et al (1985) reported a case (BB) with a similar deletion. This patient had DMD, retinitis pigmentosa, chronic granulomatous disease, and the McLeod syndrome. Our cases did not have these additional disorders, neither did they have glycerol kinase deficiency which has also been mapped to this region. We analysed BB's cells using flow cytometry which showed a similar deletion. Identification of the molecular pathology of DMD in this family maps familial DMD to $\mathrm{Xp} 21$. It gives information about the resolution of the three techniques used. Accurate carrier detection and prenatal diagnosis is possible with each. It raises questions about the discordance between our cases and BB for the additional disorders. Work is in hand to characterise the breakpoints further and to construct a DNA library from this deletion. 
Chromosome 21 specific DNA sequences and their expression in Down syndrome

L A J STEFANI*, A M MILLINGTON-WARD $\dagger$, P PEARSON $\dagger$, AND N C NEVIN*

${ }^{*}$ Department of Medical Genetics, Institute of Clinical Science, Grosvenor Road, Belfast; and tDepartment of Human Genetics, Leiden, Holland.

Down syndrome, with a prevalence of 1 to 2 per 1000 livebirths, is the most common cause of mental retardation. Mapping of the chromosome breakpoints in patients with unbalanced translocations involving chromosome 21 has demonstrated that the region $21 \mathrm{q} \cdot 22 \rightarrow \mathrm{qter}$ is responsible for the phenotypic expression of Down syndrome. A strategy has been devised for detecting and isolating low repeat and single copy expressed sequences from a chromosome 21 genomic library. Chromosome 21 sequences initially cloned into the 2 vector EMBL 3 were removed from the bacteriophage, cut with the restriction enzyme Sau3A, and subcloned into puc 12 . Transformed $E$ coli cells were screened with a Down syndrome fetal liver cDNA probe. Twelve positively hybridising clones have been analysed from the transformants and, of the six sequences so far analysed by Southern blots, all have shown single copy inserts. Northern blot analysis of three of the sequences has confirmed that they are expressed.

\section{An aetiological study of mildly mentally handicapped children \\ MARGARET A LAMONT AND N R DENNIS \\ Department of Child Health, Southampton General Hospital, Southampton.}

One hundred and sixty-nine children attending ESN/M schools were studied to assess the contribution of recognised medical factors to their retardation. Nine children had chromosomal abnormalities. One child had a familial balanced translocation, unlikely to be associated with his retardation. The others were: $47, \mathrm{XX}+21$ (2), 47, XXY (2), $48, X X Y Y, 46, X Y, d u p(14)(q 21 \rightarrow q 22), 46, X, t(X ; 19)$ (p11.2;q13.3), and 46,XX,del(15) (q11.2;q13.1). This last girl also had $\mathrm{fra}(\mathrm{X})$ in $1 / 200$ chromosomes. Biochemical studies showed no abnormalities in the children or their mothers. Five children had syndromes associated with mental retardation (Rubinstein-Taybi, Sotos, Cohen, Aarskog, and Prader-Willi). Five children had congenital brain malformations. Twelve children had identifiable preor postnatal environmental factors which could be held responsible for their retardation. An adverse perinatal history was a factor in 42 . This study led to a diagnosis of genetic aetiology being made in eight children, five with chromosomal abnormalities. We suggest that chromosomal analysis should be part of the investigation of mild mental retardation. There was a history of parental learning difficulty in 87 children. Both parents had been affected in 12 families, the mothers alone in 42 , and the fathers alone in 33. Mild mental retardation is a heterogeneous category: several children had more than one possible aetiological factor, and in these we have given only the major factor. In 44 children $(26 \%)$ there was no recognised medical factor, nor any history of parental learning difficulty.
The prevalence of the fragile $X$ syndrome in schoolchildren in Coventry

T P WEBB, S E BUNDEY, A THAKE, AND J TODD

Department of Clinical Genetics, University of Birmingham, Birmingham Maternity Hospital, Birmingham.

The fragile $\mathrm{X}$ syndrome refers to that type of mental retardation that is accompanied by the fragile site Xq27.3. A search for affected children was made in 11 special schools in Coventry. Among boys with idiopathic severe mental retardation, the frequency of the fragile X chromosome was 1 in 10 , and among those with mild mental retardation it was 1 in 16 . The fragile $\mathrm{X}$ syndrome occurred in 1 in 10 girls with idiopathic mild mental retardation. If these figures are extrapolated to the whole population of schoolchildren in Coventry, then the fragile $\mathrm{X}$ syndrome is present in about 1 in 1360 males and in about 1 in 1900 females.

Cytogenetic experience with $\operatorname{fra}(X)(q 27)$ in the west of Scotland

J M CONNOR, J M COLGAN, J A CROSSLEY, S J IMRIE, R EL MATMATI, AND E BOYD

Duncan Guthrie Institute of Medical Genetics, Yorkhill, Glasgow.

Forty-seven families with fra(X)(q27) have been assessed clinically and cytogenetically in our Department. Fortytwo of these families have the Martin-Bell syndrome (fragile $\mathrm{X}$ syndrome). Within these families all fra(X) positive males are mentally retarded but show intrafamilial variability in both the clinical phenotype and also the level of fragile $\mathrm{X}$ expression. Levels of expression in affected males have ranged from 4 to $56 \%$ with a mean of $23 \%$. Obligate carrier females who are dull or mildly retarded have all been fra $(\mathrm{X})$ positive with levels in excess of $18 \%$, whereas among obligate carriers of normal intelligence only a quarter had levels over $4 \%$ and one half were fra(X) negative. Levels appeared to be consistent on repeated sampling of a person and did not show a negative correlation with age. In five other families $\mathrm{fra}(\mathrm{X})$ is not associated with the Martin-Bell phenotype. These families are characterised by low levels ( 1 to $2 \%$ ) of fra $(\mathrm{X})$ positive cells in both males and females. The significance of this observation and its relationship to the premutation hypothesis are discussed.

Multipoint linkage analysis in families with the fragile $\mathbf{X}$ syndrome

J M CONNOR, J M COLGAN, J A CROSSLEY, S J IMRIE, AND

J R W YATES

Duncan Guthrie Institute of Medical Genetics, Yorkhill, Glasgow.

Linkage relationships have been studied for Xq DNA sequence polymorphisms in $\mathbf{1 2}$ families segregating for the fragile $\mathrm{X}$ syndrome, eight families segregating for haemophilia B, and eight three generation phase known 
normal families with three or more grandsons. Nine cloned DNA sequences which identify ten restriction fragment length polymorphisms (RFLPs) were used. DXS15 (DX13), F9 (VIII and XIII), DXS102 (cX 38・1), F8 (F8A), DXS51 (52A), DXS107 (cpX234), DXYS1 (pDP34), and DXS52 (St 14-1). The three point technique in phase known females segregating for three or more of these loci supports the order DXYS1-DXS107-DXS102-DXS51$F 9-F R A X A-D X S 52-D X S 15-F 8$. In this study the genetic distances support the conclusion that the locus for the fragile $\mathrm{X}$ syndrome lies in an area with a high recombination frequency and hence standard flanking polymorphisms are likely to be of limited clinical application for carrier detection.

\section{Accumulation of dolichol linked oligosaccharides in ceroid lipofuscinosis (Battens disease) \\ N A HALL AND A D PATRICK \\ Institute of Child Health, London.}

Ceroid lipofuscinosis $(\mathrm{CL})$ is a neurodegenerative disorder involving the accumulation of autofluorescent material in tertiary lysosomes in several tissues, particularly brain and pancreas. In both these tissues, levels of the lipid dolichyl phosphate (dol-P) were found to be 10 to 20 -fold higher in $\mathrm{CL}$ than in controls. Most of the dol-P which accumulates in $\mathrm{CL}$ is linked to oligosaccharides; indeed levels of free dol-P are comparable in CL and control brains. One of the known metabolic roles of dol-P is in the glycosylation of proteins. Oligosaccharides containing up to 14 sugar residues are assembled attached to dolichyl pyrophosphate (dol-PP) and are then transferred to proteins. The structures and sugar composition of the oligosaccharides linked to dol-PP which accumulate in CL brain have been analysed by HPLC and TLC. They would appear to include several members of the series of oligosaccharides normally assembled attached to dol-PP, but were shown to have a different size distribution from the oligosaccharides found in control brains. These results suggest that CL may result from a failure to metabolise dolichol linked oligosaccharides.

Genetic counselling in microcephaly of unknown aetiology J L TOLMIE, M B McNAY, D DOYLE, J B P STEPHENSON, AND J M CONNOR

Duncan Guthrie Institute of Medical Genetics, Yorkhill, Glasgow.

Since 1966, 38 families with the diagnosis of microcephaly of unknown aetiology have been counselled in the West of Scotland Regional Genetics Centre. In nine families, more than one child was affected and the overall empirical recurrence risk was $17 \%$. This high recurrence risk, although partly reflecting the selected nature of the referrals and small family size, also indicates a substantial genetic component with clear evidence for several different autosomal recessive entities. In 15 families, prospective ultrasonic prenatal diagnosis was undertaken in 20 pregnancies by serial measurements of head growth. Of five recurrences, four were detected in the third trimester and the fifth was missed because no scans were performed after 24 weeks' gestation. Examination of pre- and postnatal head growth records in all affected cases indicated heterogeneity with regard to the time of onset and degree of microcephaly. Thus, this study suggests that for microcephaly of unknown aetiology, there is a substantial recurrence risk and, unfortunately, second trimester ultrasonic prenatal diagnosis is not always possible.

$X$ linked hypohidrotic ectodermal dysplasia (CST syndrome): clinical and molecular study using $X$ chromosome markers

K D MACDERMOTT* AND S MALCOLM $\dagger$

${ }^{*}$ Clinical Research Centre, Harrow, Middlesex; and †Mothercare Unit of Paediatric Genetics, Institute of Child Health, London.

CST syndrome is the most commonly seen hypohidrotic ectodermal dysplasia inherited as an $\mathrm{X}$ linked recessive. The gene product is not known but the manifestation rate of the gene among obligate heterozygotes is estimated at 0.70 (Freire-Maia, 1979). At least 11 families were ascertained, where family members of three to four generations were available for study. The distribution of clinical signs among hemizygous males and obligate heterozygous carriers showed that reliable carrier detection is not possible by clinical means alone. Carrier detection is the most often requested investigation and gene assignment with a clinically useful RFLP would provide means for carrier testing. The late Dr P J L Cook first drew attenton to a female patient reported by Cohen et al (1972) with a de novo translocation between an $X$ chromosome and chromosome $9(46, X X, t(X ; 9)(q 12 ; p 24)$ who had severe manifestation of hypohidrotic ectodermal dysplasia and no family history. Dr Cook and Professor de la Chapelle suggested that the gene for this syndrome may reside at $\mathrm{Xq} 12$. Out of 11 families, seven were informative for pDP34 polymorphism. Lod score was calculated (Liped) using 15 meioses, most of which were phase known. The lod score which included DNA data on non-manifesting females $(0.70$ gene penetrance) was 2.66 at $\theta \quad 0.06$. Lod score 2.13 at $\theta \quad 0.07$ ignored data on non-manifesting females.

Epidermolysis bullosa in Southern Africa: a nationwide survey

I M WINSHIP

MRC Unit for Inherited Skeletal Disorders, University of Cape Town, South Africa.

Epidermolysis bullosa (EB) is a rare but important genodermatosis. The condition is heterogenous and several different subtypes have been delineated, some of which are potentially lethal. A nationwide study of EB in South Africa has been undertaken, in which 50 affected persons were studied. The clinical, genetic, epidemiological, histopathological, biochemical, and molecular facets of the disorder have been investigated in these persons. It has become apparent that, although uncommon, almost all the 
established subtypes of EB are present in South Africa. Despite heterogeneity, there is consistency in the manifestations of EB within any specific family. Precise diagnosis of the various forms of EB and recognition of their presence have considerable clinical and genetic implications.

\section{Mosaicism and prenatal diagnosis}

M A C RIDLER AND M S GREWAL

The Kennedy-Galton Centre, Harperbury Hospital, Harper Lane, Radlett, Herts.

The occurrence of mosaicism in a series of 5889 amniocenteses is presented. There were seven true mosaics, 46 pseudomosaics, and 35 maternal contaminations detected. In three true mosaics and three pseudomosaics there were discrepancies between amniotic cells, fetal cells, and chorion. There were seven undetected errors but only one (a false positive) had a serious outcome. In 157, abnormal karyotypes were found. In a separate series, 41 fetuses were examined. Twenty-six of these had chorion biopsies and skin and chorion could be compared in 19 cases. Of these, two showed mosaic aneuploidy in fetal skin and abnormal amniotic cells but normal chorionic cells.

Post-termination examination of abnormal fetuses aborted following amniocentesis or ultrasound scan D DONNAI, P A FARNDON, AND C M E McKEOWN

Department of Medical Genetics, St Mary's Hospital, Manchester.

In a three year period 258 mid-trimester fetuses were received for examination from hospitals in the North Western Region. Data on 130 terminated for abnormality diagnosed by amniocentesis and scan are presented. Routine examination includes detailed external examination, anthropomorphic measurements, karyotype analysis, and photographs; other investigations are done as indicated. All fetuses are then examined internally by members of the Department of Paediatric Pathology. Sixtyeight fetuses were terminated following test on amniotic fluid ( 31 chromosome abnormality, 28 neural tube defect, nine others); the post-termination examination confirmed the diagnosis in 65 and significantly altered it in three. Sixty-two fetuses were terminated following scan diagnosis of abnormality (37 NTD, 25 others). In 23 the diagnosis was significantly changed or refined in a way which affected genetic counselling. This study demonstrates the need for careful examination of terminated fetuses both for accurate genetic counselling and for quality control for the tests employed.

Mitotic and meiotic studies in a familial three way translocation (9q;13q;12q)

E PASSARGE* AND R JOHANNISSON $\dagger$

${ }^{*}$ Institut für Humangenetik, Universitätsklinikum Essen, 4300 Essen; and +Institut für Pathologie, Medizinische Universität Lübeck, Lübeck.

Through a child with multiple congenital malformations, proven to have an additional derivative chromosome 9 , we ascertained a family with a complex three way translocation. The proband was the only unbalanced member of the family. Seven other members in three generations were heterozygous for a reciprocal balanced translocation involving chromosomes 9,12 , and 13 . The distal long arm of a chromosome 13 (beyond 13q32) was translocated onto the long arm of a chromosome 9 at $9 q 22$, the distal half of that chromosome (beyond $9 q 22$ ) was translocated onto the long arm of chromosome 12 at $12 \mathrm{q} 22$, and the distal third of that chromosome (beyond 12q22) was translocated onto the chromosome 13. Recurrent spontaneous abortions occurred in two female heterozygotes and unexplained infertility in one male heterozygote. Meiotic studies from a testicular biopsy of this man revealed complex pairing patterns at pachytene. All three homologous chromosome pairs formed hexavalent closed or open circles. Different patterns with respect to the synaptonemal complex were observed. The karyotype of the proband is interepreted as a consequence of meiotic malsegregation as has been observed in Robertsonian translocations in the mouse.

The problem of apparently isolated cases of Huntington's chorea in South Wales

o QUARRELL*, A TYLER*, G COLE $\dagger$, AND P S HARPER*

*Section of Medical Genetics; and +Department of Pathology, University of Wales College of Medicine, Heath Park, Cardiff.

A firm diagnosis of Huntington's chorea is based upon both clinical observation and a positive family history. A total of 192 cases of Huntington's chorea occurred in South Wales over a 10 year period fitting both criteria but, despite detailed enquiries, an additional 37 patients did not have affected relatives. Twenty-two of these were still thought to have Huntington's chorea on clinical grounds while this diagnosis was thought less likely for 15 . Definite outcomes in terms of postmortem are known for eight patients and the clinical diagnosis was confirmed on six occasions. Details regarding these two groups are presented, together with an additional case in which Huntington's chorea occurred on the death certificate but necropsy revealed a diagnosis of Kuf's syndrome.

\section{A clinical and genetic linkage study of a kindred with a Marfan like syndrome \\ J S BAMFORTH* ${ }^{*}$, P TSIPOURAS $\dagger$, A L BORRESEN $\ddagger$, AND P S HARPER* \\ ${ }^{*}$ Section of Medical Genetics, University of Wales College of Medicine, Cardiff; †Rutgers Medical School, New Jersey, USA; and $¥ A$ vdeling for Medisinsk Genetik, Oslo, Norway.}

A large three generation Welsh kindred with an autosomal dominantly inherited Marfan like syndrome has been studied. Affected subjects are tall and exhibit dolichostenomelia, arachnodactyly, and upward dislocation of the lens. Severe eye problems are the rule with high myopia and retinal tears. Blindness is common in 
older members. The facies are characteristic with deep set eyes, prominent supraorbital ridges, prominent nose, and a long face. The syndrome differs from typical Marfan syndrome by the absence of any cardiac or aortic involvement (including echographic evidence); scoliosis is also absent. In members over the age of 25 years there are progressive musculoskeletal symptoms with pain and limitation of movement involving the large joints and the spine. Linkage studies using cDNA collagen gene probes are being undertaken. There has been at least one cross over observed with the pro $\alpha 2(\mathrm{I})$ probe. Studies with the pro $\alpha 1$ (III) probe and the elastin probe are in progress.

\section{A 'new' syndrome of peroneal muscular atrophy with pyramidal signs, mental retardation, and optic atrophy K D MACDERMOTT* AND R W WALKER $\ddagger$ \\ ${ }^{*}$ Clinical Research Centre, Harrow, and the Kennedy- Galton Centre, Harperbury Hospital, Radlett, Herts; and tThe National Hospital for Nervous Diseases, Queen Square, London.}

Two brothers and their female cousin with mental retardation, optic atrophy, and distal muscle wasting are described. They come from a large pedigree of Gujarati Muslims where consanguinity is high. Autosomal recessive inheritance is suggested. Peroneal muscular atrophy (PMA) is a descriptive term for a heterogeneous group of disorders which were classified into several distinct groups according to electrophysiological and genetic criteria. The commonest forms are hereditary motor and sensory neuropathy types I and II and the distal form of spinal muscular atrophy (Harding and Thomas, 1980). Rarely, hereditary neuropathy has been described in combination with CNS involvement. Examples are PMA with pyramidal features (Dyck and Lambert, 1961; Harding and Thomas, 1984), PMA and optic atrophy (Dyck, 1984), and PMA with deafness and retinitis pigmentosa. We report a syndrome of slowly progressive distal muscle wasting with pathologically brisk tendon reflexes. The nerve conduction and sensory action potentials are within normal limits. However, sural nerve biopsy showed gross fall out of sensory fibres. This family represents an unusual combination of hereditary neuropathy with normal nerve conduction velocity and loss of sensory fibres, together with evidence of CNS involvement, as indicated by optic atrophy and mental retardation.

Three children with $\alpha_{1}$-antitrypsin deficiency, $P i Z$ null: case reports and review

F BAMFORTH*, N KALSHEKER*, AND S BAMFORTH ${ }^{*}$

*Department of Medical Biochemistry, Cardiff Royal Infirmary; and +Department of Medical Genetics, University Hospital of Wales, Heath Park, Cardiff.

Alpha $_{1}$-antitrypsin (AAT) is a major inhibitor of serine protease and deficiency is associated with an increased risk of pulmonary emphysema in adults and of liver disease in childhood. The $\mathrm{Pi}$ null allele $(\mathrm{Pi}-)$ for AAT is a rare cause of AAT deficiency and is associated with absent AAT production. Subjects homozygous for the null allele develop pulmonary emphysema in early adulthood, but do not suffer from liver disease. There are few reports of persons heterozygous for both $\mathrm{Pi} \mathrm{Z}$ and $\mathrm{Pi}$ null alleles, and it is therefore difficult to define distinctive clinical features of the condition. We describe clinical features in three children with AAT deficiency; $\mathrm{Pi} Z$ null. All have respiratory symptoms, predominantly recurrent bronchitis with wheezing, and all have biochemical evidence of liver dysfunction, although only one child had clinical liver disease. We conclude that early respiratory impairment and liver dysfunction are likely manifestations of the $\alpha_{1}$ antitrypsin $\mathrm{Pi} \mathrm{Z}$ null phenotype.

\section{Von Hippel Lindau disease}

S M HUSON*, R D WEEKS $\dagger$, D A S COMPSTON $\ddagger$, AND P S HARPER*

*Section of Medical Genetics, †Department of Neurosurgery, and $\ddagger$ Department of Neurology, University of Wales College of Medicine, Heath Park, Cardiff.

Von Hippel Lindau (VHL) disease is an autosomal dominantly inherited multisystem disorder, the commonest presenting manifestations of which are haemangioblastomas of the cerebellum and retina. Affected subjects are at risk of developing a number of other lesions, the most serious of which are renal cell carcinoma, other haemangioblastomas of the central nervous system, and phaeochromocytoma. During the last five years, six cases of VHL disease have presented to the neurosciences department in Cardiff. Four of these have been referred for genetic counselling. They and their relatives at risk are now being reviewed on an annual basis so that disease manifestations can be recognised at an early stage. Screening of relatives at risk in these families has demonstrated one asymptomatic renal cell carcinoma which was removed. Our experience of VHL disease indicates that annual screening of known cases and their at risk relatives should be performed by retinal examination, biochemical screening for phaeochromocytoma, and CT scans of the head and abdomen.

Linkage analysis using nine DNA polymorphisms along the length of the $X$ chromosome locates the gene for EmeryDreifuss muscular dystrophy to distal Xq

S V HODGSON, E BOSWINKEL, A WALKER, M BOBROW, K DAVIES, V DUBOWITZ, G GRANATA, AND L MERLINI

Guy's Hospital Medical School, London; Hammersmith

Hospital, London; John Radcliffe Hospital, Oxford; and Instituto Ortopedica Rizzoli, Bologna, Italy.

Emery-Dreifuss muscular dystrophy (EDMD) is an $\mathrm{X}$ linked recessive condition characterised by mild muscular weakness predominantly in a scapuloperoneal distribution with variable facial involvement. Onset is in childhood with slow progression of weakness. There is early develop- 
ment of contractures, especially at elbows and ankles, with rigidity of the spine. Myocardial involvement with cardiac conduction defects occurs and may require pacemaker insertion. Mental retardation is not a feature. Evidence for linkage between EDMD and deutan colour blindness was observed in one large pedigree (Thomas et al. J Neurol Neurosurg Psychiatry 1972;35:208) where all five affected males were colour blind. We have searched for linkage between DMD and nine different polymorphic DNA probes which span the length of the $\mathrm{X}$ chromosome and have analysed $\mathrm{Xg}$ types in three EDMD families. The evidence is that EDMD does not segregate with probes on Xp known to be linked to DMD and Becker dystrophy. With probes DX13 and ST14, localised close to Xqter, there were two recombinants out of 16 informative meioses. Taken together with the family of Thomas $e t$ al, this suggests a separate dystrophy locus for EDMD towards the telomere of $\mathrm{Xq}$. 